\title{
PATHOGENESIS OF MITRAL STENOSIS
}

- BY

F. R. MAGAREY, M.D., M.R.C.P., M.R.A.C.P.

(From the Department of Pathology and Bacteriology, Welsh National School of Medicine, Cardiff)

\section{[With Photogravure Plate]}

Little attention has been paid in modern times to the pathological changes which underlie the progressive nature of the stenosis occurring in rheumatic mitral disease. This problem has now become of practical importance, because with modern cardiac surgery it is possible to obtain direct relief of the condition by operation on the affected valve.

\section{Current Theories}

There are two main views regarding the pathogenesis of chronic rheumatic valvalar thickening and stenosis. Rokitansky (1852) was of the opinion that the valves became thicker in consequence of the deposition on the surface of the cusps of layers of a morbid substance from the blood which becomes converted into fibrous tissue. He also believed that this same process caused the cusps to become adherent to one another by means of repeated deposition in the commissures between them. On the other hand, the usual present-day conception of the process attaches little significance to organization of fibrin on the surface of the valve. Rather it is thought that the necrosis and inflammation which go on within the substance of the valve cusps cause the cicatricial contraction. Coombs (1924) described this process as a purse-string gradually tightening around the orifice of the valve. I believe that there is ample evidence to show that progressive post-rheumatic valvular thickening and development of mitral stenosis are due, at least in part, to organization of repeated deposits of fibrin on the surface of the valve and in the commissures between the cusps as described by Rokitansky, and that it is not necessarily dependent upon the more generally accepted process of postinflammatory cicatricial contraction within the substance of the valve.

\section{Evidence}

It is not now in general dispute that the thrombi forming the typical vegetations of acute rheumatic endocarditis become covered by endothelium and organized by the growth of fibrous tissue during the healing stage. This process will inevitably lead to the formation of fibrous bosses and irregularities on the auricular surface of the cusps. It is not these vegetations with which we are concerned, but the repeated deposits of fibrin which occur after the acute phase is over. In a previous investigation, in which 250 mitral valves from routine necropsies were examined, I showed that $7 \%$ bore fibrin deposits on the surface (Magarey, 1949). Only a small number of valves in this series were stenotic, and as the deposits also occurred on normal valves they are not to be regarded as pathognomonic of the chronic stage of the rheumatic process. Further investigation, during which about 30 rheumatic valves were examined, has shown that fibrin deposition on the surface of the cusps is far more common on rheumatic than on non-rheumatic valves. In fact, instead of the $7 \%$ in non-rheumatic valves, the frequency of ozcurrence is nearer $70 \%$ in the rheumatic cases. It is possible that the deformities associated with the healing stage of acute rheumatic fever described above encourage deposits of fibrin on the surface, and this sequence of thrombus formation followed by organization may be repeated throughout life, thus explaining the slow development of mitral stenosis over a number of years.

When sections from chronic rheumatic valves are studied there is a good deal of evidence to support this view. It can be seen that the deposits of fibrin which are often present become covered by endothelium extending from the contiguous surface of the cusp, and that fibroblasts from the pre-existing tissue gradually replace the plaque of fibrin by a layer of firm fibrous tissue. Some sections of thickened valves show this process to have been recurrent, the deeper layers of fibrin being in a more advanced stage of organization than the superficial (Plate, Fig. 1). This repeated fibrin deposition followed by replacement with fibrous connective tissue leads not only to thickening of the cusps but also to gradual narrowing of the valve orifice by a silting-up process.

I have previously made another observation which supports this view. Lambl's excrescences, small tags of endothelium-covered fibro-elastic tissue, occur commonly on the auricular surface of normal mitral valves. They are primarily superficial structures, but in sections of thickened valves they are sometimes seen partly buried within the substance of the valve. Even when so buried they are still readily recognizable by their histological architecture (Fig. 2). This partial submergence is further proof of repeated depositions of fibrin in the neighbourhood, the ensuing organization of these layers of fibrin leading to the gradual burial of these structures beneath the surface of the cusps.

If the commissures between the valve cusps are examined in specimens of established mitral stenosis, in more than half of the cases adhesions are seen between the adjacent surface of the cusps. These adhesions are the result of fibrin clot formation on the endocardium of the valve followed by organization, and it has been possible to demonstrate all stages of this process during the examination of this series of about 30 stenotic valves (Figs. 3 and 4). The process, when often repeated, will lead to gradual constriction of the orifice of the valve, and thus to the further development of stenosis. This opinion is contrary to that of Coombs. He states that organization of adhesions does not contribute to the approximation of the segments of the mitral valve at their ends, although he believes that fusion of the neighbouring parts of two cusps of the aortic valve may be due to this process.

The development of thickening of the valve and obliteration of the angles of junction of the cusps continues in the absence of any prolongation or recrudescence of the acute inflammatory stage of rheumatic valvulitis, and it can be demonstrated to be progressing years after there has been any history of acute manifestations of rheumatic fever. The slow but relentless development of mitral stenosis for many years after an attack of acute rheumatic fever can be thus explained.

\section{"Shortening" of the Chordae Tendineae}

The same process of surface fibrin deposition followed by organization can account for the so-called "shortening" of the chordae tendineae and for the adhesions that form between them in chronic rheumatic 
disease of the mitral valve. A gelatinous deposit of fibrin can sometimes be found adhering to the chordae tendineae, binding them together (Fig. 5). In this fibrin early organization may be present, and the end-results of this process are the formation of firm fibrous adhesions between the chordae. The same process taking place near the attachment of the chordae tendineae to the valve cusp will cause adhesions not only between the chordae themselves but also between them and the ventricular surface of the valve. In sections of some greatly thickened valves the chordae can be seen deeply buried in the substance of the cusp (Fig. 6). This condition could scarcely occur by any means other than organization of repeated surface deposits which eventually causes the various structures to become enveloped in a continuous fibrous coveting. The fusion of the valvular attachment of the chordae tendineae to the back of the cusp will give the appearance of shortening and will at least accentuate any real shortening of the chordae which may occur by any other means.

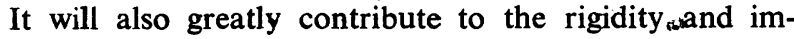
mobility of the cusps and thus to the stenosis.

\section{Conclusion}

The conception of the pathogenesis of mitral stenosis which I have described has an added interest in view of the findings at operations undertaken for the direct surgical relief of the condition such as described by Baker, Brock, and Campbell (1950). The technique they favour is that of digital dilatation of the valve, the result of such procedure being a splitting of the stenosed valve along the line of the pre-existing commissures. This is the site where one would expect the tissues to give way had the commissures become occluded by fibrous adhesions as already described, and if, as is suggested, this is one of the main causes of the stenosis, relief would be expected from this operation. Glover, Bailey, and O'Neill (1950) describe the use of a specially designed knife to cut the commissures. Apart from those in the addendum their series consists of 50 cases, but the longest post-operative follow-up is only two years. It remains to be seen for how long the stenosis is alleviated by these manipulations. If the above conception of the process of the disease is correct, it is to be expected that the lesion may recur because the irregular surface of the cusps will still predispose to repeated thrombus formation.

\section{Summary}

Evidence is produced to show that the long-continued progression of stenosis in rheumatic mitral disease is due, at least in part, to organization of repeated deposits of fibrin on the surface of the valve and in the commissures between the cusps.

In view of this mode of progression it seems that mitral stenosis relieved by digital dilatation and splitting, as recently described, may be expected to recur.

I am very grateful to Professor Jethro Gough for his advice in the preparation of this paper, and to Mr. J. P. Napper for his assistance with the photography.

\section{REFERENCES}

Baker, C., Brock, R. C., and Campbell, M. (1950). 'British Medical Journal, 1, 1283 .

Coombs, C. F. (1924). Rheumatic Heart Disease. Wright, Bristol Glover, R. P. Bailey, C. P., and O'Neill, T. J. E. (1950). J. Amer. med. Ass., 144, 1049

Magarey, F. R. (1949). J. Path. Bact., 61, 203.

Rokitansky, C. (1852). A Manual of Pathological Anatomy, vol. 4. Translated by George E. Day. London.

\section{USE OF GALLAMINE TRIETHIODIDE (FLAXEDIL) IN MODIFYING E.C.T.}

\author{
A COMPARISON WITH D-TUBOCURARINE \\ CHLORIDE AND DECAMETHONIUM IODIDE
}

BY

\author{
O. S. THOMPSON, M.R.C.S., L.R.C.P. \\ Anaesthetist, London Hospital
}

AND

\author{
ALAN, NORTON, D.M., D.P.M. \\ Chief Assistant, Department of Psychiatry, London Hospital
}

Since the introduction of convulsion treatment for the psychoses in 1934 by Meduna, the technique of administration and the indications for its use have undergone progressive modification. The main steps have been the development by Cerletti and Bini in 1938 of electrical methods of provoking a convulsion, the extension of the treatment to out-patients, and the use of curare and other drugs to reduce the severity of the muscular contractions during the convulsion.

\section{D-Tubocurarine Chloride}

With the unmodified technique, still probably employed as a routine in most hospitals and clinics, and despite the use of some method of physical restraint, the incidence of fractures remains appreciable. Hobson and Prescott (1947), in their report on the use of D-tubocurarine chloride, showed that with an unmodified technique the incidence of crusb fractures of the dorsal vertebrae remains at about $4 \%$, but other writers have reported higher figures. Although it is agreed that these particular fractures have little clinical importance, and rarely lead to any lasting disability, they are of medico-legal importance, and other injuries are less innocent clinically. We do not yet know for certain that these vertebral fractures will not in fact lead to an arthritis some years hence. Although Thorpe (1948) seems to be satisfied with his unmodified technique, and reports no complications or fractures in the course of 3,000 convulsions, this is hardly the experience of the majority of those who carry out that treatment.

Until the introduction of curare as a means of modification there were always patients whose psychiatric condition demanded convulsion treatment, but who had to be denied it because their physical condition absolutely precluded its use. Shepherd and Watt (1949) reported a series of 50 patients successfully given electric convulsion treatment modified by $\mathrm{D}$-tubocurarine chloride who would have been untreatable owing to physical disease had some method of modifying the convulsion not been employed.

The injection of curare and drugs with a similar action in a conscious patient produces a terrifying sensation (Hobson and Prescott, 1947 ; Davies and Lewis, 1949 ; Guild, 1950), and in practice such injections are therefore combined with a simultaneous injection of thiopentone. E.C.T. has long been criticized because in a fair proportion of patients it produces a dread that is severe enough to cause some to refuse further treatment ; Cooper (1948), Thorpe (1948), and many others have used thiopentone by itself to diminish this fear. The use of thiopentone with a curarizing agent has this 


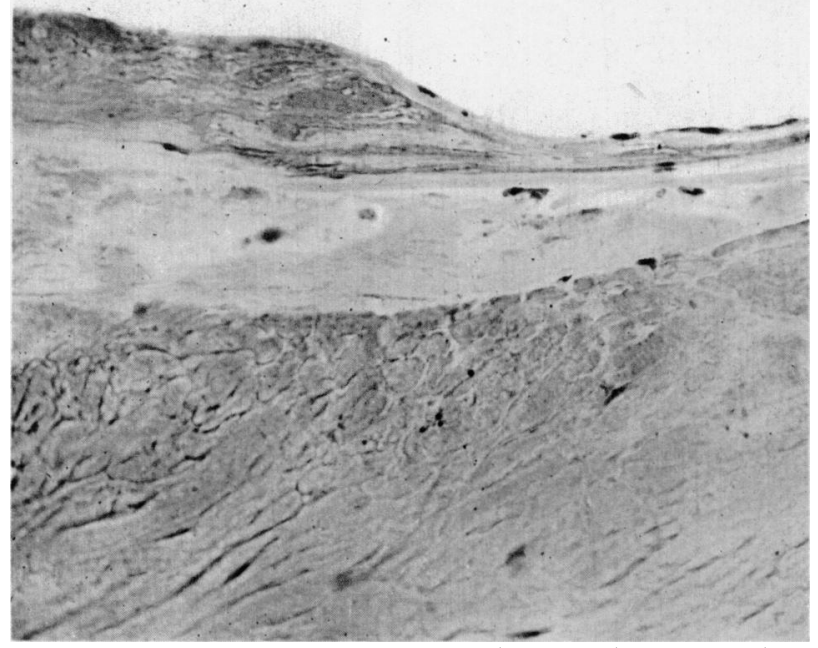

FIG. 1.-Thin deposits of fibrin on surface of valve. Organization represented by underlying pale zone. Frozen section.

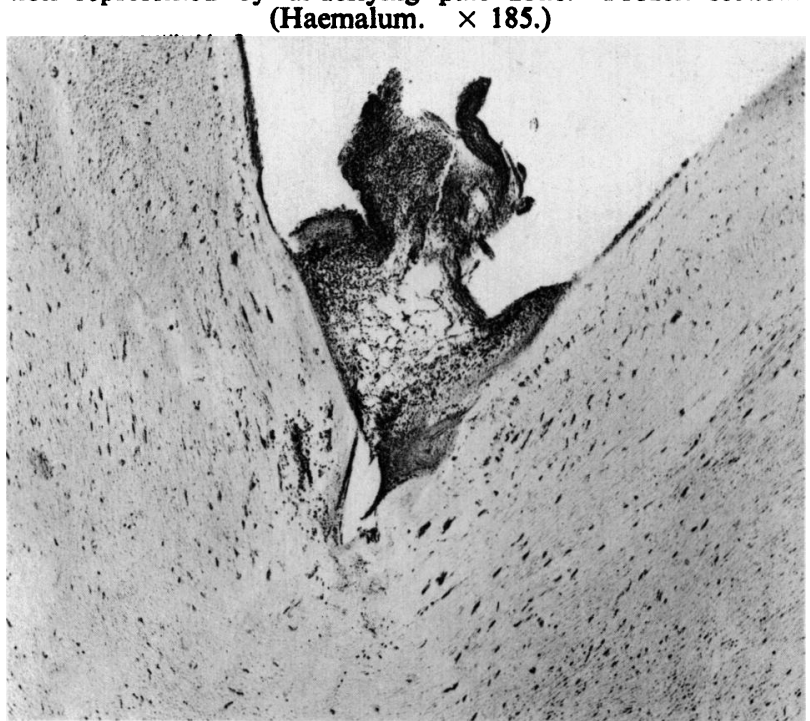

FIG. 3.-A recent fibrin deposit in a commissure causing the two cusps to become adherent. Frozen section. (Haemalum. $\times$ 48.)

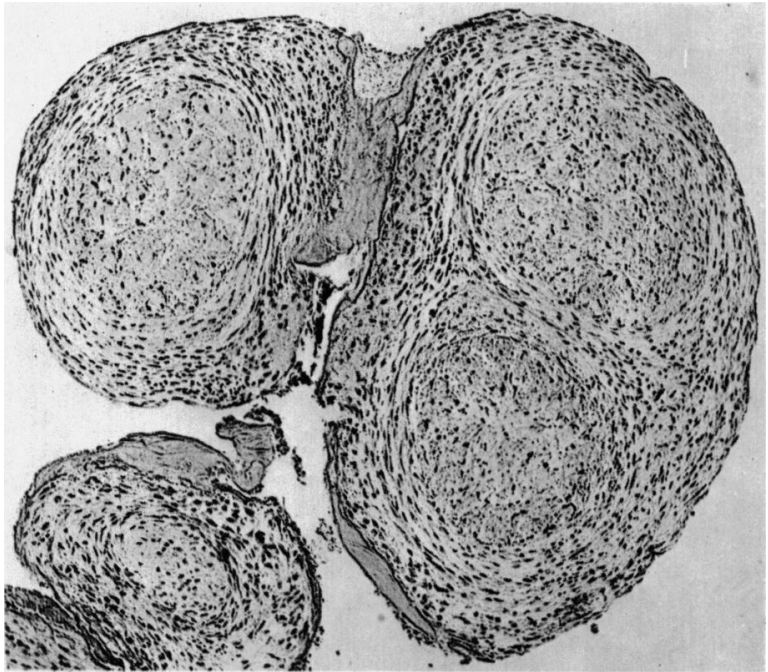

FIG. 5.-From a case of acute rbeumatic fever. Chordae tendineae bound together by fibrin deposits in which organization is starting. (Haemalum and eosin. $\times 82$.)

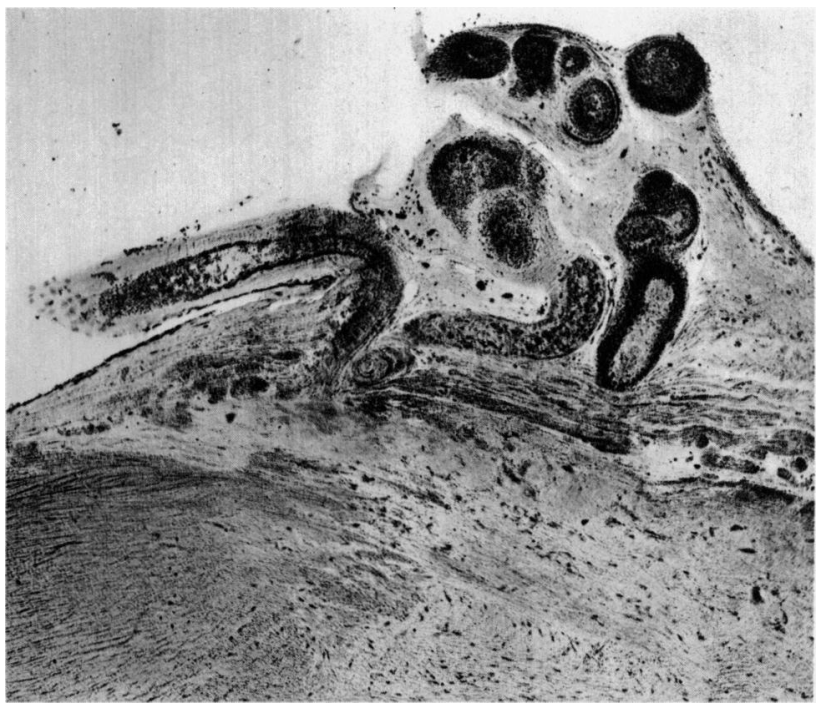

Fig. 2.-Lambl's excrescences cut at various angles. Portions of some are buried beneath surface of valve. Frozen section. (Haemalum. $\times$ 44.)

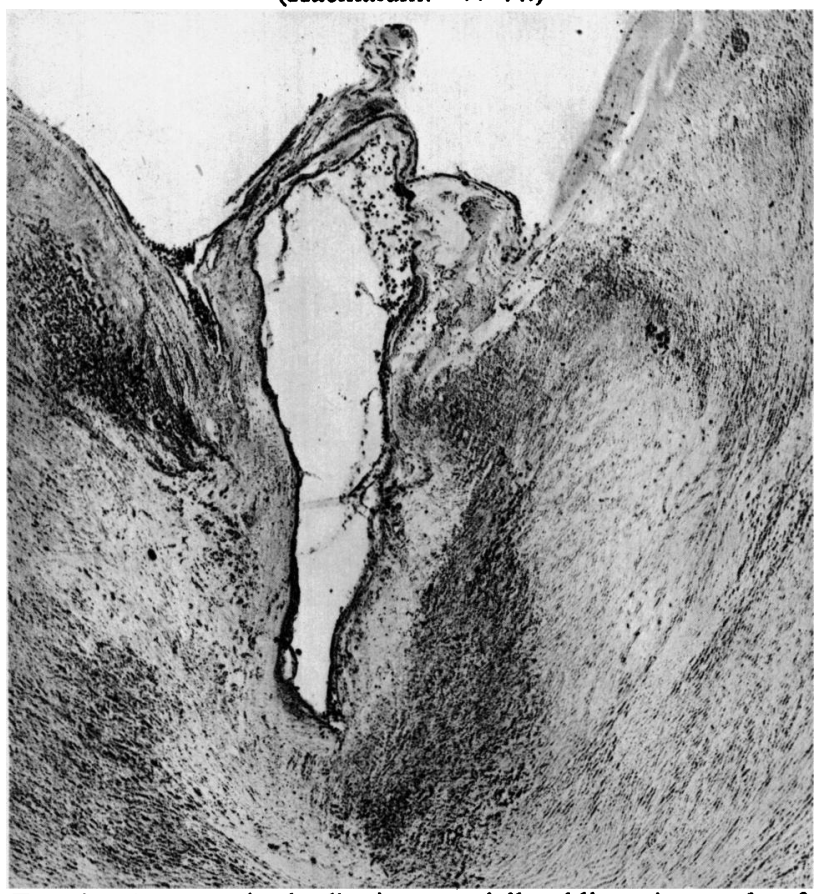

FIG. 4.-An organized adhesion, partially obliterating angle of commissure between the cusps. Frozen section. (Haemalum:

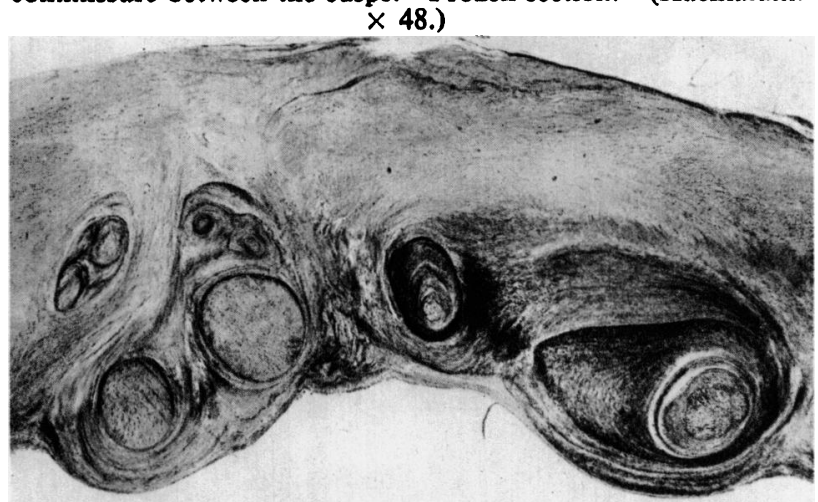

Fig. 6.-Section through a thickened cusp. Chordae tendineae buried in ventricular aspect of cusp. Frozen section. (Haemalum and elastic stain. $\times 12$.) 